book quite fails to meet. It starts with a pedestrian but well-referenced chapter on quantal calculations, which omits the estimation of dispersion forces from transition moments, and overlooks the existence of multibody forces in condensed systems. It starts to go badly wrong when it gets to experimental methods and their interpretation. Inversion of macroscopic properties to give intermolecular potentials is wrongly described as "rarely successful", electronic spectroscopy of dimers is dismissed in seven lines, and molecular beams in two pages. The section on the determination of intermolecular forces from viscosity is so misjudged that it quotes equations appropriate to the theory of the viscosity of liquids whilst only gases have been used for this purpose. The final chapter, "Applications", has some more interesting pages but it is often uncritical and repetitious. Even the useful information in the book is difficult to find without an index of systems. This disappointing book can be recommended neither to chemists nor to biologists.

J.S. Rowlinson is Dr Lee's Professor of Chemistry in the University of Oxford, UK.

\section{Thirst work}

\author{
M.J. McKinley \\ and J.F. Nelson
}

The Physiology of Thirst and Sodium Appetite. By J.T. Fitzsimons. Pp.572. (Cambridge University Press: Cambridge, UK, 1979.) £32.50.

RENEWED interest in the study of thirst mechanisms has resulted from the experimental contributions made over the past two decades by James Fitzsimons. The last major work on this subject, Thirst by A.V. Wolf (Charles C. Thomas: Springfield,
Illinois, 1958), appeared more than 20 years ago and, in view of the burgeoning experimental activity in this field since then, Fitzsimons' new book is a timely and comprehensive account of knowledge on thirst.

His book is the latest of the series of monographs published by the Physiological Society. Designed primarily for readers at the level of graduate student and above, it gives a lucid analysis of the causes of drinking, discusses the comparative physiology of drinking in vertebrates, dissects the effect of cellular and extracellular dehydration, and assesses the roles of hormones and the reninangiotensin system on drinking behaviour. A survey of the pharmacology of drinking

\section{Hagfishes and lampreys}

\section{Lis Olesen Larsen}

Biology of the Cyclostomes. M.W. Hardisty. Pp.428. (Chapman and Hall: London, 1979.) £20.

THOSE who wish to elucidate the early stages of vertebrate phylogeny often examine only one, or at most two, cyclostome species. Further, such studies have too often been based on a few animals, badly described as to prehistory, stage of development, sex etc. This makes much of the ample literature on cyclostomes (hagfishes and lampreys) rather superficial. Professor Hardisty, however, has spent a lifetime in devoted study of many aspects of lamprey ecology, physiology and morphology. Recently retired, he has made in this book an impressive effort to summarize what is known about lampreys and hagfishes. His main intention is to discuss the early stages of vertebrate phylogeny by comparing all aspects of the two groups. His basic assumption is that although cyclostomes are no longer considered directly ancestral to the gnathostomes, they are more likely to have retained characters of "the unknown vertebrate ancestor" than other vertebrate groups.

Each chapter compares lampreys and hagfishes, and the topics range from palaeontology, ecology, physiology and morphology, to biochemistry and molecular biology. In a final chapter Hardisty tries to draw conclusions about evolution on the basis of an integrated view of the life of hagfishes and lampreys. Thanks to his honest discussions, this chapter made it clear to me (but not to him) that his basic assumption is not necessarily true. The probability of finding primitive characters in present-day vertebrates may be equally our hypotheses about evolutionary pathways are always marred by the difficulties in distinguishing between primitive and specialized characters, and in knowing when changes are adaptive (that is caused by natural selection) and when they occur by chance. The latter possibility is not seriously considered by Hardisty.

Throughout the book the author lists differences, between lampreys and hagfishes and between cyclostomes and gnathostomes, in attempts to establish how these three groups relate to one another. In order to obtain knowledge about the vertebrate ancestor(s?) it may be equally useful to look for similarities among these three groups, and between each of them and the various invertebrate and protochordate groups.

The book is recommended for all who want to study cyclostomes. They will find a useful, broad and detailed basis for their studies and an updated list of references. []

Lis Olesen Larsen is an Associate Professor at the Zoophysiological Laboratory, August Krogh Institute, University of Copenhagen, Denmark. large in any vertebrate group. In addition and clinical aspects of thirst is included as well as a chapter on sodium appetite.

It is perhaps an unfortunate necessity that, as recognized by the author, the book is no more than an interim account. Thus few of the more than 700 references cited are to results published by others during the last three years. As a consequence, for example, the importance placed by him on the renin-angiotensin system as a stimulus to thirst would now be disputed by a number of other investigators in the field.

The chapter on sodium appetite has a number of deficiencies. This is primarily a consequence of defining sodium appetite as "an innate response to sodium deficiency, that causes animals to seek and ingest sodium salts", a restrictive definition. Thus evidence which demonstrates clearly that glucocorticoids stimulate sodium appetite has been overlooked. In fact the author claims that "glucocorticoids have little if any action on sodium appetite". It also appears to be inconsistent with such a definition that he recognizes that sodium appetite increases in both rats and rabbits during pregnancy and lactation where the changes are almost certainly due to alterations in hormone secretion and not to sodium deficiency.

The synthesis of the large salt appetite of pregnancy and lactation by appropriate sequential administration of physiological amounts of steroid and peptide hormones has been shown. The experiments closely parallel those on induction of maternal behaviour by similar hormone dosage. They hardly leave any conclusions on the role of these hormones as hazardous, as the author suggests, unless quite different criteria are applied to those advanced by him for a physiological role of angiotensin in thirst. Some minor inconsistencies and errors (e.g. p. 100 lists plasma $\mathrm{K}$ of humans as $6.3 \mathrm{mM}$ ) in the text were also noted.

Despite these limitations the book makes a very significant contribution to the dissemination of knowledge in this rapidly advancing area of physiology, and will no doubt become a standard reference work on thirst.

M.J. McKinley is a C.J. Martin Research Fellow and J.F. Nelson a Senior Research Officer of the National Health and Medical Research Council of Australia. Both are employed at the Howard Florey Institute of Experimental Physiology and Medicine, University of Melbourne, Victoria, Australia. 